\title{
A PiggyBac mediated approach for lactoferricin gene transfer in bovine mammary epithelial stem cells for management of bovine mastitis
}

\author{
Neelesh Sharma ${ }^{1,2, *}$, Do Luong Huynh ${ }^{1, *}$, Sung Woo Kim ${ }^{3}$, Mrinmoy Ghosh ${ }^{1}$, \\ Simrinder Singh Sodhi ${ }^{1}$, Amit Kumar Singh ${ }^{1}$, Nam Eun Kim ${ }^{1}$, Sung Jin Lee ${ }^{4}$, Kafil \\ Hussain ${ }^{2}$, Sung Jong $\mathrm{Oh}^{5}$ and Dong Kee Jeong ${ }^{1}$ \\ ${ }^{1}$ Department of Animal Biotechnology, Faculty of Biotechnology, Jeju National University, Jeju, Republic of Korea \\ ${ }^{2}$ Division of Veterinary Medicine, Faculty of Veterinary Science \& Animal Husbandry, Sher-e-Kashmir University of Agricultural \\ Sciences \& Technology of Jammu, Jammu, India \\ ${ }^{3}$ Animal Genetic Resources Station, National Institute of Animal Science, Rural Development Administration, Namwon, \\ Republic of Korea \\ ${ }^{4}$ Department of Animal Biotechnology, College of Animal Bioscience and Technology, Kangwon National University, Chuncheon, \\ Republic of Korea \\ ${ }^{5}$ National Institute of Animal Science, Wanju-gun, Republic of Korea \\ *These authors have contributed equally to this work \\ Correspondence to: Dong Kee Jeong, email: newdkjeong@gmail.com, dkjeong@jejunu.ac.kr \\ Keywords: antibacterial milk peptide; bovine lactoferricin; PiggyBac; bovine mastitis; antibacterial activity \\ Received: August 29, $2017 \quad$ Accepted: September 21, $2017 \quad$ Published: October 31, 2017 \\ Copyright: Sharma et al. This is an open-access article distributed under the terms of the Creative Commons Attribution License \\ 3.0 (CC BY 3.0), which permits unrestricted use, distribution, and reproduction in any medium, provided the original author and \\ source are credited.
}

\section{ABSTRACT}

The antibacterial and anti-inflammatory properties of lactoferricin have been ascribed to its ability to sequester essential iron. The objective of the study was to clone bovine lactoferricin (LFcinB) gene into PiggyBac Transposon vector, expression study in the bovine mammary epithelial stem cells (bMESCs) and also to determine the antimicrobial property of recombinant LFcinB against bovine mastitis-causing organisms. The PiggyBac-LFcinB was transfected into bMESCs by electroporation and a three fold of LFcinB secretion was observed in the transfected bMESCs medium by ELISA assay. Furthermore, the assessment of antimicrobial activity against mastitis causing pathogens Staphylococcus aureus and Escherichia coli demonstrated convincing evidence to prove strong antibacterial activity of LFcin B with $14.0 \pm 1.0$ $\mathrm{mm}$ and $18.0 \pm 1.5 \mathrm{~mm}$ zone of inhibition against both organisms, respectively. The present study provides the convincing evidence to suggest the potential of PiggyBac transposon system to transfer antibacterial peptide into bMESCs or cow mammary gland and also pave the way to use bovine mammary gland as the bioreactors. Simultaneously, it also suggest toward commercial utilization of LFcinB bioreactor system in pharmaceutical industry.

\section{INTRODUCTION}

Infectious diseases constitute a pertinent concern in Human and Veterinary Medicine worldwide. Bovine mastitis is an inflammatory disease of udder caused by multietiolgical agents but Staphylococcus aureus (S. aureus) and Escherichia coli (E. coli) are primarily responsible for the immensity of bovine mastitis cases $[1$,
2]. S. aureus is a normal inhabitant of the udder [3], and $E$. coli is found in the animal's environment. The unbounded use of antimicrobials to hamper microbial growth have bestowed to the development of bacterial resistance against a broad spectrum of antibiotics.

Lactoferrin (LF) is a multifunctional protein found in bovine milk [4] with an antimicrobial properties: it is active against many Gram-negative and Gram-positive 
bacteria [5], viruses [6], and various types of fungi and parasites $[7,8]$. Owing to its antibacterial activity, that would be a promising candidate to replace conventional therapy used for bovine mastitis treatment. Various therapeutic properties of LF have been described in details in a recent review paper [9]. The antimicrobial peptides (AMPs) in modern pharmaceutical research play the vital role for human and veterinary medicine. These peptides show a broad spectrum of antimicrobial activity and can also trigger specific defense responses in the host. The earlier evidence suggested that AMPs showed high effectiveness against pathogens in mastitic bovine milk and low efficiency in milk from healthy cows. In present study, the functional potential of antibacterial peptide LFcinB in inflammatory responses and the expression profiling in bovine mammary epithelial stem cells was investigated. Moreover, the AMPs present the advantage of being derived from a harmless and inexpensive source and have therefore an undeniable potential for use in medicine [10].

Numerous theories have been postulated on the antibacterial mechanism of action of AMPs and found that they exert their action on the cytoplasmic membrane of susceptible microorganisms [11]. Later different molecular mechanisms of membrane perturbation by antimicrobial peptides have increased our understanding toward the most exact mechanism of action $[11,12]$ viz. pore formation on the bacterial membrane by thinning the membrane or destabilizing the membrane bilayer [13, 14]. Other theories suggested that AMPs have bactericidal activity through inhibition of macromolecule biosynthesis or by interacting with specific vital components inside the microorganism, or both [15].

Bovine lactoferricin (LFcinB) is a peptide fragment produced by acid-pepsin hydrolysis of lactoferrin obtained from cow's milk [16]. LFcinB, which consists of 25 amino acid residues (17 to 41 ) proximal to the $\mathrm{N}$-terminus of bovine lactoferrin, is notable for its ability to bind iron and relatively have high proportion and asymmetrical clustering of basic amino acid residues. LFcinB has attracted considerable interest because of its well established antimicrobial activity $[17,18]$. Owing to its potential antimicrobial and immunomodulator activity, it is necessary to produce more this bioactive peptide from the mammalian system for further studies and clinical trials. Therefore, this study was aimed to increase antibacterial ability of mammary epithelial cells through increased secretion of the antibacterial agent (LFcinB) and to provide strong innate udder immunity to fight against intramammary infections. The present study was focused on the synthesis of a fragment from $17-41$ amino acids and to investigate the ability of bovine mammary epithelial stem cells for expression, secretion, production and antibacterial activity of LFcinB to combat with major mastitis causing organisms. Due to high milk production ability, bovine mammary gland can be used as bioreactors, and are supposed to be the feasible tools for the production of LFcinB in large scale for pharmaceutical industry. The construction of an efficient and specific eukaryotic expression vector is a key regulatory point for the development of a mammary gland as a bioreactor.

To the best of our knowledge, this is the first report on the heterologous expression of the hybrid antibacterial peptide LFcinB into PiggyBac system with high antibacterial properties against bovine mastitis origin $S$. aureus and E. coli and also provides the basis for next cost-effective expression of other antimicrobial peptides in genetic engineering. Recent genetic studies have also suggested that PiggyBac can be used as potential alternate of viral vectors for the gene therapy and transgenic production.

\section{RESULTS}

\section{Construction of PiggyBac-LFcinB recombinant}

The pGEM-B1 plasmid containing LFcinB was identified using bovine lactoferricin detection primer (Figure 1A). The amplified gene fragment of $449 \mathrm{bp}$ was visualized on $1.5 \%$ agrose gel electrophoresis (Figure 1B). The expression vector PiggyBac was digested with the restriction enzymes EcoRI and BamHI. The amplified fragment of the synthetic gene was ligated into PiggyBac vector and the recombinant fragment was named as PiggyBac-LFcinB. The gene products were popped out by the restriction digestion to confirm the presence of the gene fragments in the respective vector (Figure 2A). Simultaneously, the incorporation of the gene into 106 the vectors was confirmed by PCR amplification from the recombinant plasmid with specific forward and reverse primers (Figure 2B). The length of $449 \mathrm{bp}$ suggested ligation of gene of interest into the PiggyBac vector.

The quality of the recombinant was confirmed by DNA sequencing and clone was evaluated using sequencing chromatogram. The result has been shown by using Finch TV software, and the sequence was evaluated again by BLASTn (www.blast.ncbi.nlm.nih.gov/Blast. cgi?PAGE_TYPE=BlastSearch). It was found that the sequence data has shown $100 \%$ similarity with original gene sequence with the $449 \mathrm{bp}$ length. Therefore, there is no doubt that the quality of the clone produced is under best quality score.

\section{LFcinB transfected stable cell lines}

The transfection results demonstrated the expression of Green Fluorescent Protein (GFP) of recombinant bovine lactoferricin after $48 \mathrm{~h}$ of transfection with 15 $20 \%$ transfection efficiency in the bMESCs (Figure 3A), whereas positive control Pmax GFP showed about 30-35\% (Figure 3B). After $48 \mathrm{~h}$ transfection, cells were subjected for selection with $250 \mu \mathrm{g} / \mathrm{ml}$ puromycin as a selection 


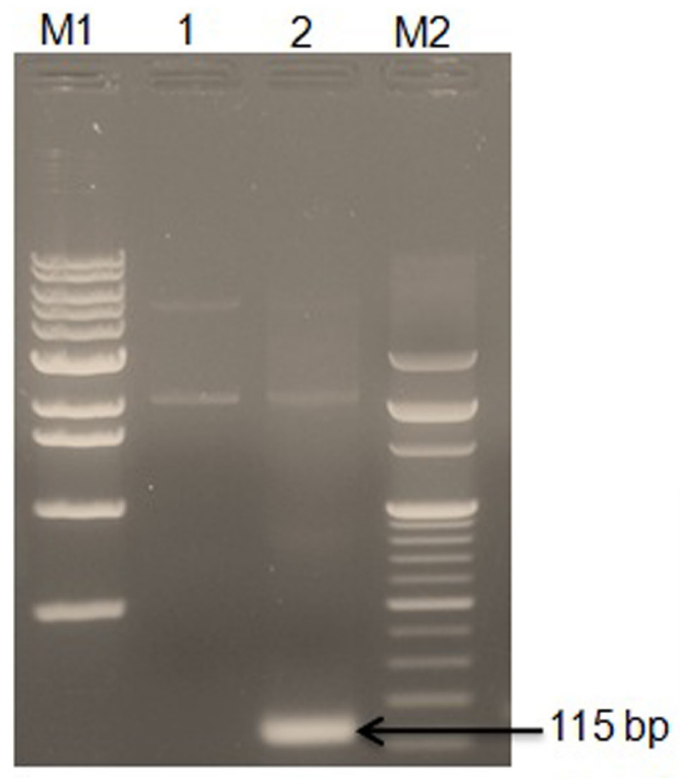

A

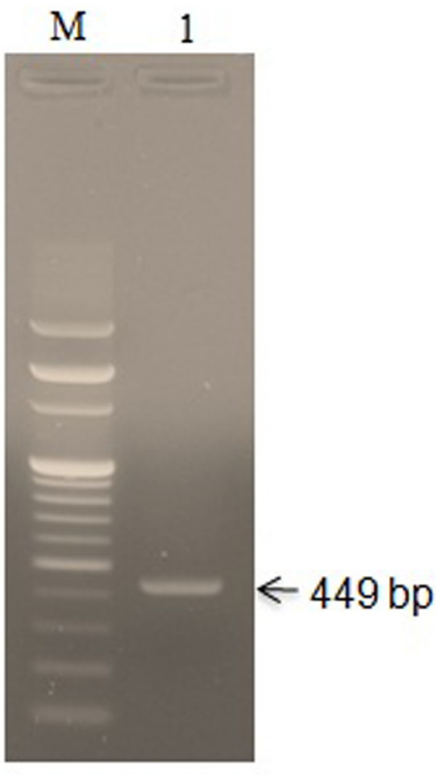

B

Figure 1: PCR detection and amplification of LFcinB gene in the pGEM-B1 plasmid. Panel A: PCR detection of bovine lactoferricin gene in the pGEM-B1 vector with detection primer. Lane M1- 1 kb DNA ladder; Lane 1- pGEM-B1 vector with $L F c i n B$ gene; Lane 2- PCR detected $L F c i n B$ gene (115 bp) and Lane M2- 100 bp DNA ladder. Panel B: PCR amplification of bovine lactoferrin gene from the pGEM-B1 vector using cloning primer. Lane M- $100 \mathrm{bp}$ DNA ladder and Lane 2- PCR amplified lactoferrin gene (449 bp).

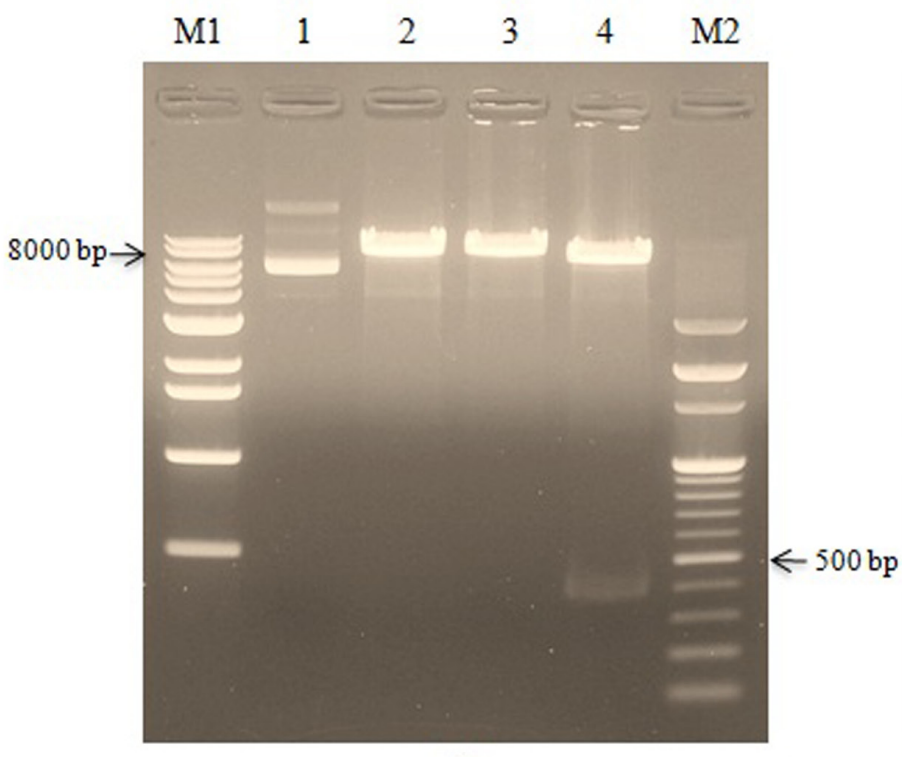

A

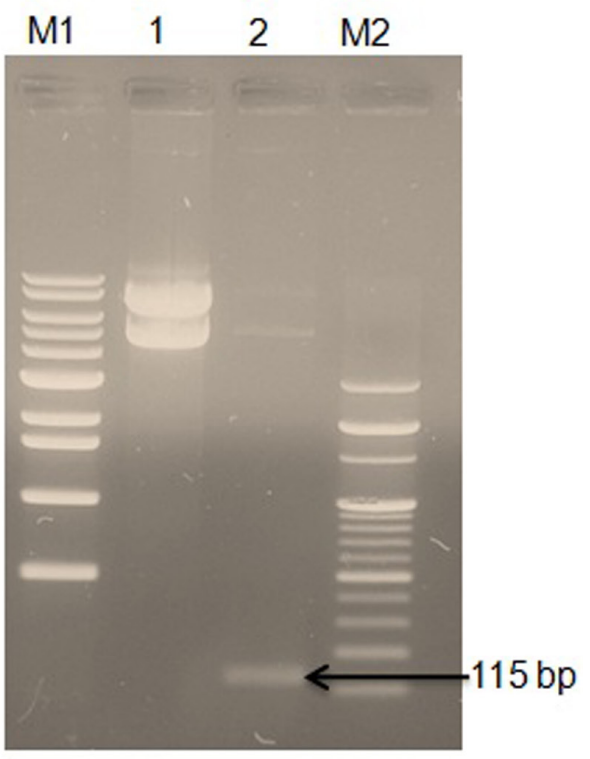

B

Figure 2: Confirmation of bovine lactoferricin ligation in the recombinant PiggyBac-LFcinB plasmid by restriction enzymes and PCR. Panel A: Confirmation of bovine lactoferricin ligation by restriction enzymes. Lane M1- 1Kb DNA marker; Lane 1- Undigested recombinant plasmid (PiggyBac-LFcinB); Lane 2- Single digestion of recombinant plasmid with BamHI; Lane 3- Single digestion of recombinant plasmid with EcoRI; Lane 4- Double digestion of recombinant plasmid with BamHI and EcoRI; Lane M2- 100 bp DNA ladder. Panel B: Confirmation of bovine lactoferricin ligation by PCR. Lane M1- 1 kb DNA marker; Lane 1- Undigested recombinant plasmid (PiggyBac-LFcinB); Lane 2- PCR detected LFcinB gene (115 bp); Lane M2- 100 bp DNA marker. 
marker in mammalian cells and purified colonies were obtained within 2 weeks (Figure 3C, 3D). Puromycin resistant pure cells were picked up and transferred to fresh medium for multiplication and finally LFcinB purified cells were obtained. All these in together suggest that the utilization of PiggyBac system is exceeding compared to normal vectors. That partly demonstrated that PiggyBac is one of a powerful tool for transfection of mammalian cells. The purified transfected cells were used for further analysis and determination of lactoferricin production.

\section{Transfectants produce high quantity of LFcinB in the medium}

The dramatic increase of LFcinB secretionwas noticed in the transfected BMESCs in in-vitro culture system. In the non-transfected cell, the concentration of LFcinB in the medium was found to be $2 \mu \mathrm{g} / \mathrm{ml}$ whereas transfected cells had three folds higher LFcinB production ability (Figure 4). It suggests that the LFcinB transfected cells may be used as good source of LFcinB with antibacterial property and can protect mammary gland from intramammary infections by providing innate immunity. The increased production of LFcinB has gained a significant interest to study the antibacterial efficacy of LFcinB in transfected cells media as such.

\section{Detection of $L F$ cinB in the stable cell lines by immunocytochemistry}

The purified colonies of LFcinB transfected cells were subjected to immunochemical analysis for further confirmation of cloning and transfection. Transfected cells were immunostained with anti-bovine lactoferricin antibody and further staining with phycoerythrin conjugated anti-mouse antibody emitted red fluorescence under microscope (Figure 5I) and confirmed the successful transfection of LFcinB and its expression into bMESCs. Figure 5II shows green fluorescence signals of the recombinant LFcinB clone (GFP) as a control without
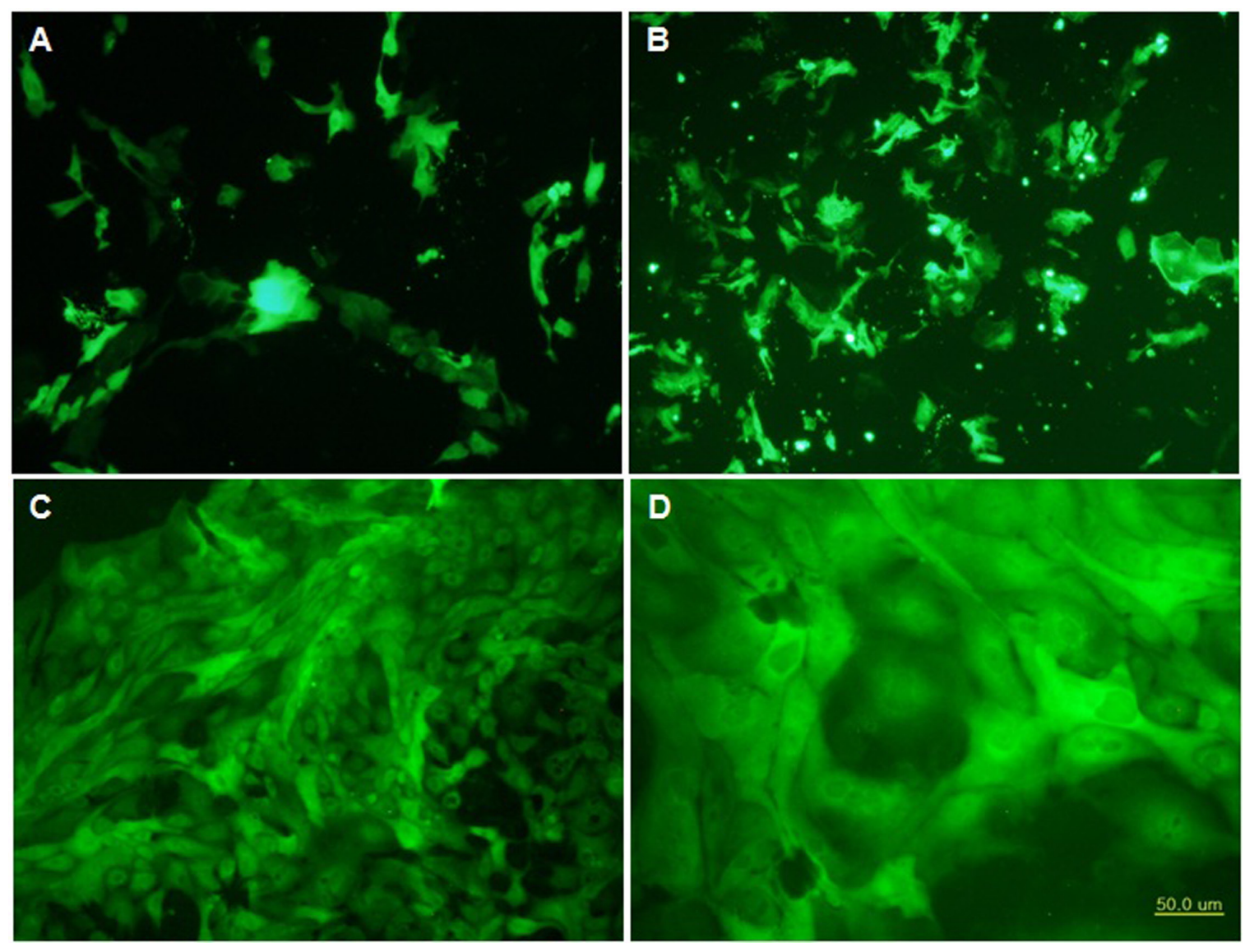

Figure 3: Transfection, expression and establishment of bovine mammary epithelial stable cell lines with recombinant PiggyBac-LFcinB. (A) Expression of Pmax GFP (positive control) after $24 \mathrm{~h}$ of transfection (100x); (B) Expression of recombinant bovine lactoferricin GFP after $24 \mathrm{~h}$ of transfection (100x); (C) Purified recombinant bovine lactoferricin cell line after 14 days of transfection in puromycin as selection marker (100x); (D) Purified recombinant bovine lactoferricin cell line after 14 days of transfection in puromycin which was used as selection marker at high resolution (200x). Cells showed the clear morphology of bovine mammary epithelial stem cells with nucleus and nucleolus. 
staining with primary antibodies and thus confirmed the transfection. These results further confirmed the successful cloning of LFcinB and the potential of PiggyBac to express the insert in transfected bMESCs.

\section{Antibacterial activity of $L F \operatorname{cin} B$}

Antibacterial activity for produced LFcinB was assessed by agar well diffusion assay as are shown in
Figure 6. LFcinB exhibited higher antibacterial efficacy against $E$. coli compared to $S$. aureus. The zone of inhibition observed as a result of LFcinB activity against $S$. aureus growth was $14.0 \pm 1.0 \mathrm{~mm}$ (Figure $6 \mathrm{Aa}$ ), while that for standard antibiotic (positive control) was $23.7 \pm$ $1.5 \mathrm{~mm}$ (Figure 6Ab). There was no growth inhibition in negative controls i.e. phosphate buffer saline (PBS; Figure 6Ac) and media from non-transfected cells (Figure 6Ad). Similar trend were observed for E. coli, where LFcinB had

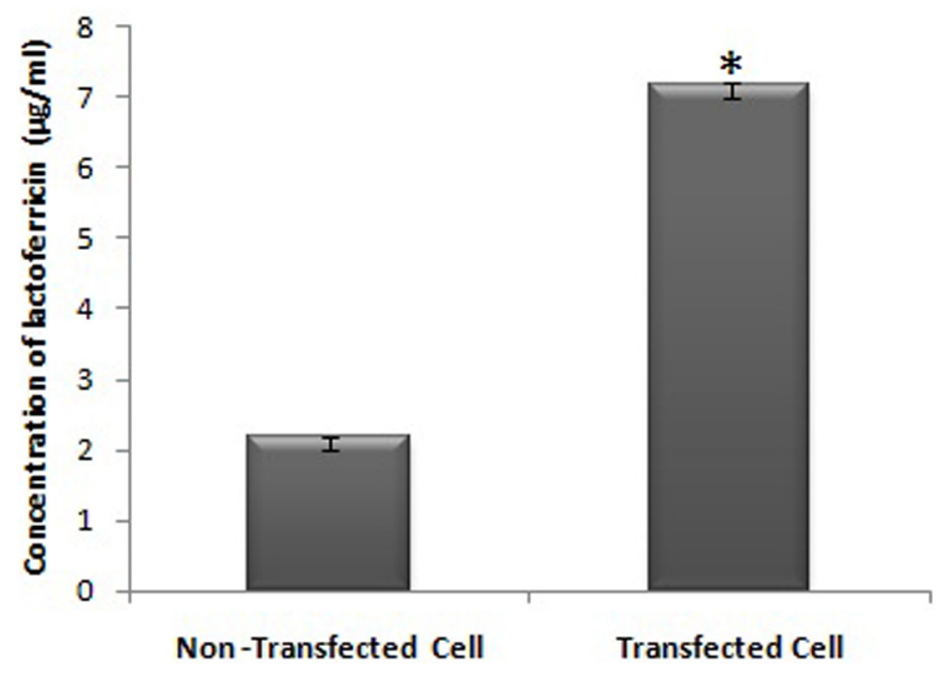

Figure 4: Bovine lactoferricin secretion ability of transfected cells and detection of its concentration in the cell culture medium of transfected and non-transfected bMESCs $(\mathrm{P} \leq 0.05)$.
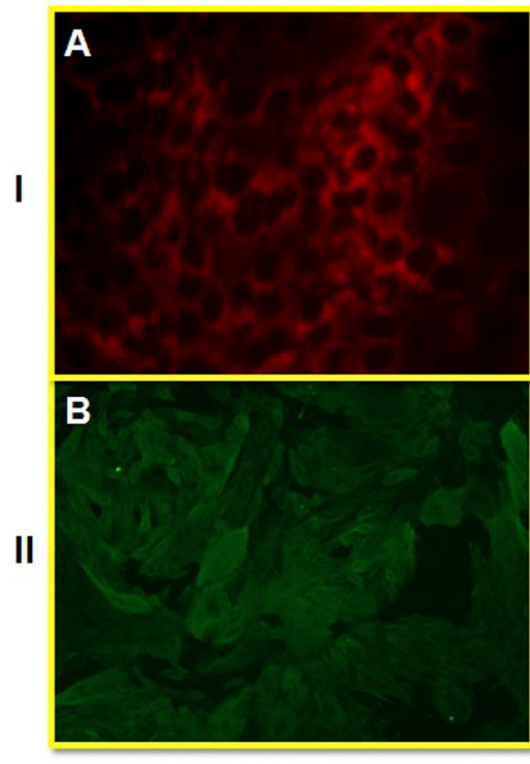
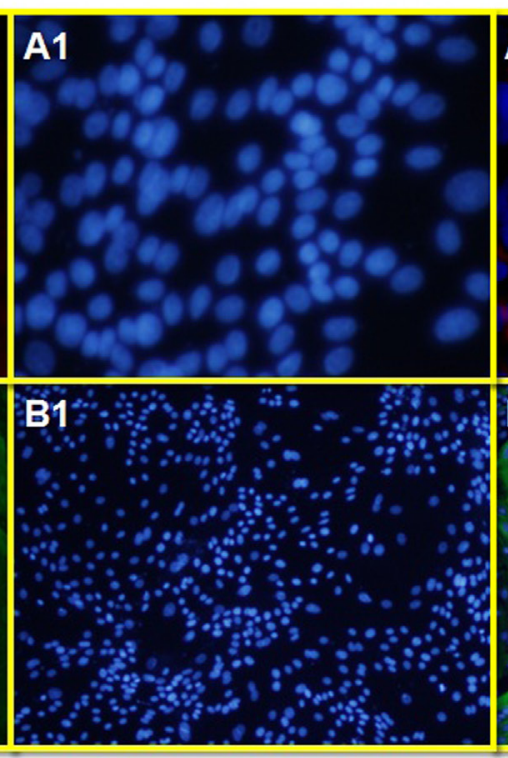
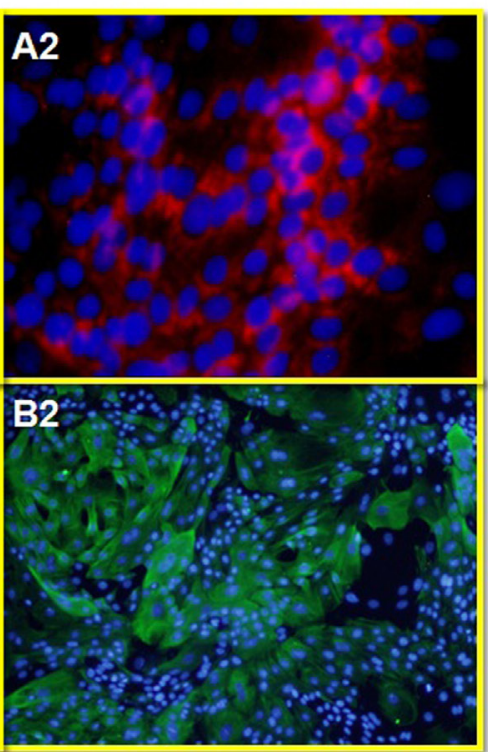

Figure 5: The presence of red fluorescence signals of bovine lactoferricin primary antibody as a marker of successful transfection in cultured bovine mammary epithelial stem cells (bMESCs). Panel I: Transfected bMESCs immunostained with mouse primary antibody anti-Bovine Lactoferricin and goat anti-mouse secondary antibody conjugated with Phycoerythrin (PE) showing red fluorescence (A), DAPI nuclear staining (A1) and merged (A2) (100x). Panel II: Transfected bMESCs immunostained without primary antibody (as control) showing only green signals of recombinant LFcinB, while no signals of goat anti-mouse secondary antibody conjugated with Phycoerythrin (PE) (B), DAPI nuclear staining (B1) and merged (B2) (200x). 
$18.0 \pm 1.5 \mathrm{~mm}$ (Figure 6Ba) zone of inhibition and were comparable to antibiotic positive control $(23.1 \pm 0.9 \mathrm{~mm})$ (Figure 6Bb) while no inhibition was observed in control wells (Figure 6Bc, 6Bd). The results of micro-dilution assay and agar-well assay were strong indicative of the antibacterial activity of bovine lactoferricin.

The antimicrobial kinetic study of recombinant bovine lactoferricin was performed by broth microwell assay, and the growth of bacteria was determined at different time points. Data obtained from these assays established that LFcinB has strong antibacterial activity against both $S$. aureus (Figure 7A) and E. coli (Figure 7B) when compared to control. Absorbance values obtained from LFcinB treated group were compared with those obtained for the standard antibiotic treated group against both isolates. The results of the kinetic study clearly confirmed the antibacterial activity from 4 to $5 \mathrm{~h}$ onward.

\section{DISCUSSION}

Bovine lactoferricin is a 25 amino acid residue peptide released from lactoferrin upon pepsin digestion [19]. Lactoferrin is the major iron binding protein in milk of many mammalian species, has shown strong cationic antimicrobial property against a wide range of microorganisms including Gram-positive and Gram negative [20-24]. Earlier studies have confirmed that lactoferrin may have therapeutic potential in mastitis $[25,26]$. Moreover, Wall et al. [27], has been produced a genetically enhanced cows resist intramammary
Staphylococcus aureus infection with targeting lysostaphin transgene. Transgenesis has been suggested as a means to combat mastitis [28]. Recent studies have been used lactoferricin as anti-bacterial agent against diarrheal organisms (S. aureus and E. coli) [29, 30].

Lactoferricin is widely distributed, but it is difficult and time-consuming to isolate lactoferricin directly from natural sources. Therefore, it would be an imperative and worth trying to realize the expression and purification of recombinant lactoferricin with low cost and high bioactivity via modern biotechnology. Zhang et al. [18], used plasmid-mediated gene transfer technique to enable mammary cells to synthesize and secrete bovine lactoferricin and bovine tracheal antimicrobial peptides to prevent bovine mastitis.

The present study was focused on the antibacterial activity of lactoferricins in bovine mammary epithelial stem cells against major mastitis causing bacteria. The LFcinB gene was cloned into the PiggyBac vector system. We transfected the PiggyBac- LFcinB clone in vitro into bMESCs and results were analyzed by immunocytochemistry. The strong GFP expression and immunochemistry results have shown that the gene has been successfully integrated into the genome of transgenic cells and highly expressed.

Transposable elements have been routinely used for genetic manipulation in lower organisms. In contrast, the usage of transposons in vertebrate systems is still limited [31]. Because of low transfection or hard to transfect primary mammary epithelial cells, researchers are using viral transfection systems. Hence it was decided to move
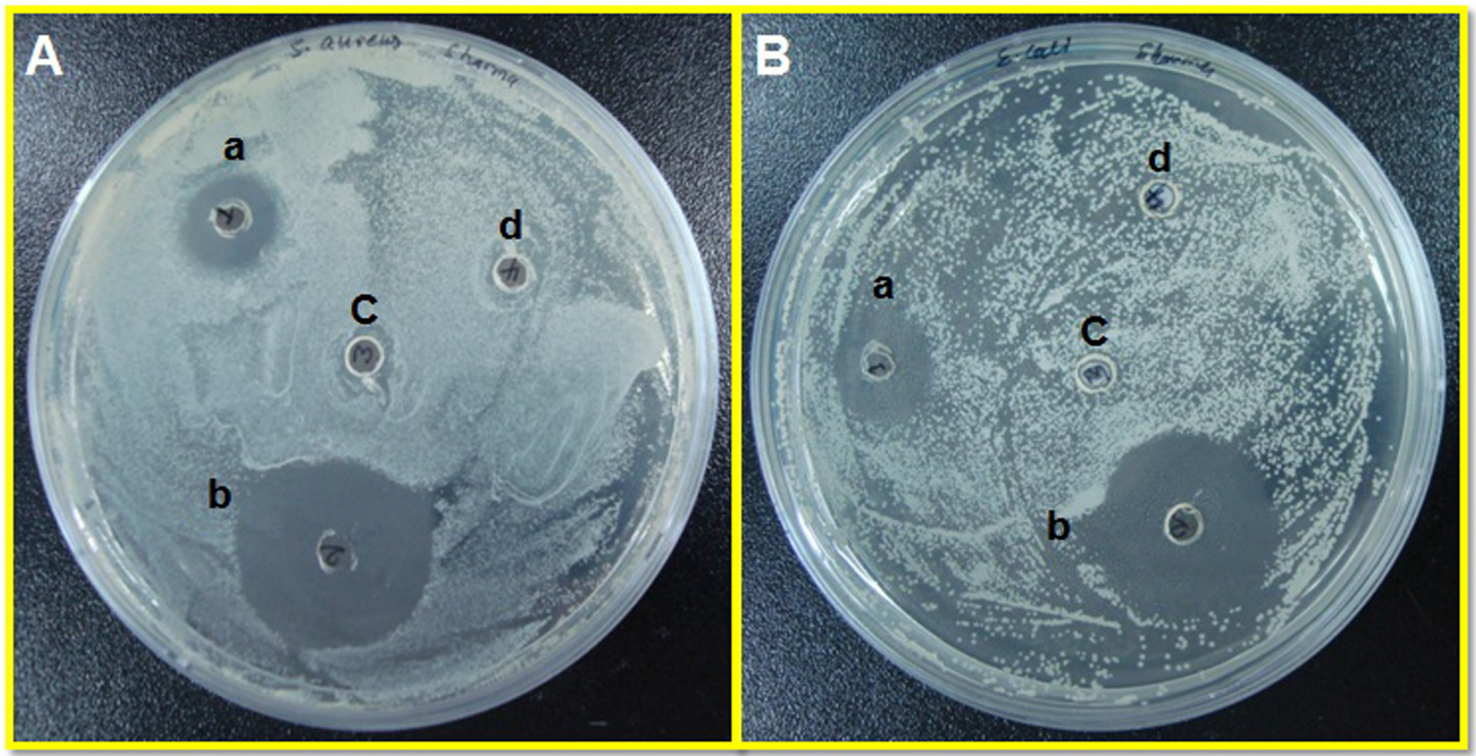

Figure 6: Evaluation of antibacterial activity of recombinant LFcinB against bovine mastitis-causing Gram positive and Gram negative bacteria by agar well diffusion assay. Plates showing susceptibility to LFcinB secreted by transfected cells in media (a) against both $S$. aureus (A) and $E$. coli (B). A strong zone of inhibition with Penicillin-Streptomycin (50 $\mu \mathrm{g} / \mathrm{ml})$ as positive control (b) and no zone of inhibition with media from non-transfected cells (c) and PBS (d) as negative controls. 
one step further by using non-viral vector with potential transfection efficiency in bMESCs. Long-term expression of a transgene is most reliably achieved by the stable integration. Retroviral and lentiviral vectors have been used for this purpose, but their cargo capacity is limited to $10 \mathrm{~kb}$, and they are not suited for the delivery of intron-containing cargos. Moreover, most important is that these viral systems have an immunogenic and tumorigenic potential [32]. The PiggyBac transposase is an efficient gene transfer vector active in a variety of cell types and proven to be amenable to modification [33]. The recent study has shown the efficient application of PiggyBac mediated transposition
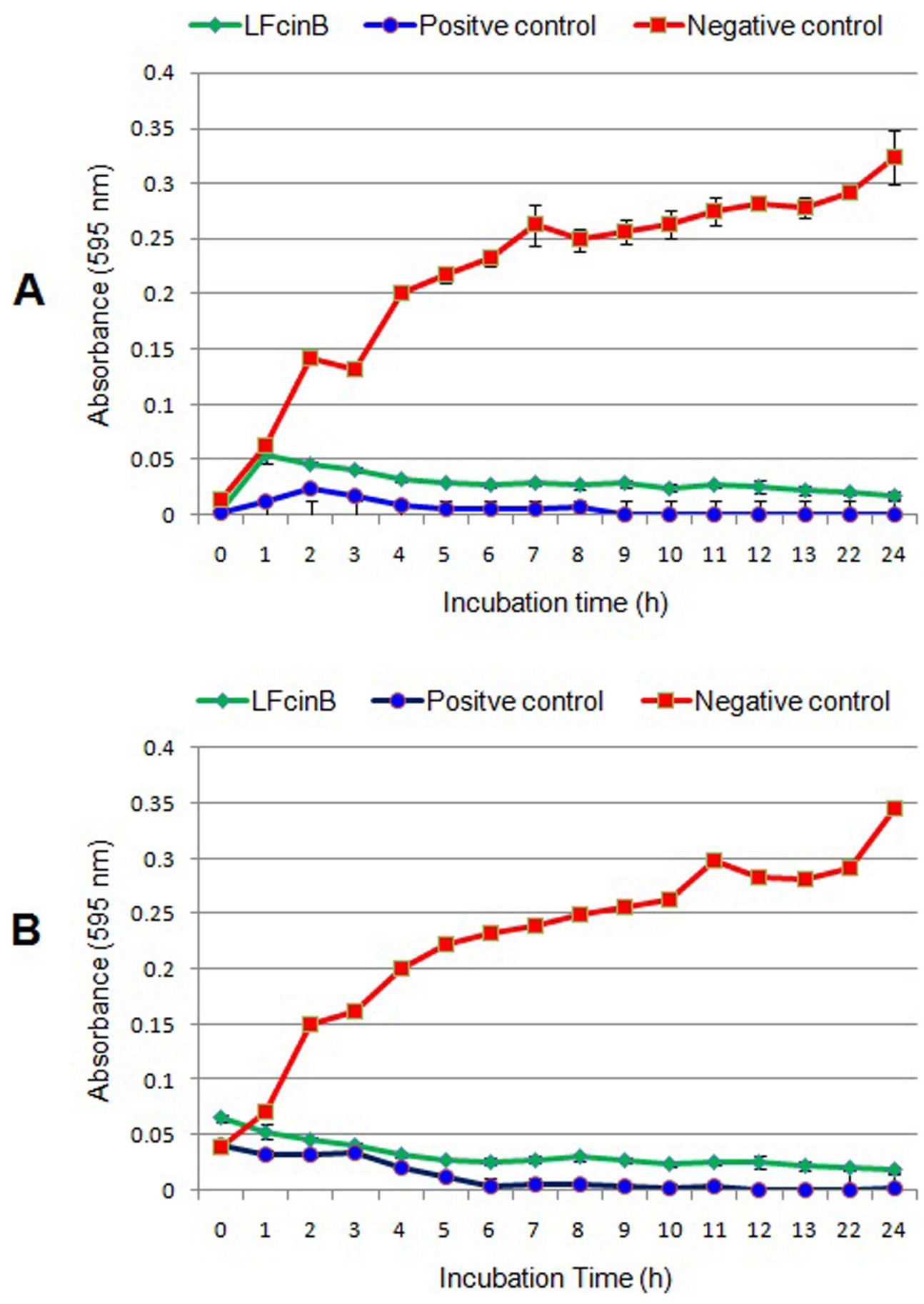

Figure 7: Antibacterial kinetic study of bovine lactoferricin against mastitis causing bacteria by broth micro well assay. S. aureus (panel A) and E. coli (panel B) $\left(1 \times 10^{5} \mathrm{CFU}\right)$ were treated with media from recombinant PiggyBac-LFcinB transfected and non-transfected cells, incubated at $37^{\circ} \mathrm{C}$ for $24 \mathrm{~h}$. Penicillin-streptomycin $(50 \mu \mathrm{g} / \mathrm{ml})$ was used as positive control. Optical density of bacterial growth at different time intervals. 
vector in the germ cells of chicken [34] and production of bovine induced pluripotent stem cells (iPSCs) [35]. The DNA transposon PiggyBac is widely used as an efficient tool in mammalian experimental systems for transgenesis, mutagenesis and genome engineering [36]. This study showed that PiggyBac is more efficiently expressed in mammary cell lines of bovine and is amenable to further molecular modification without reducing its activity [37]. The present research work provides a powerful approach to enhance the properties of the PiggyBac system for
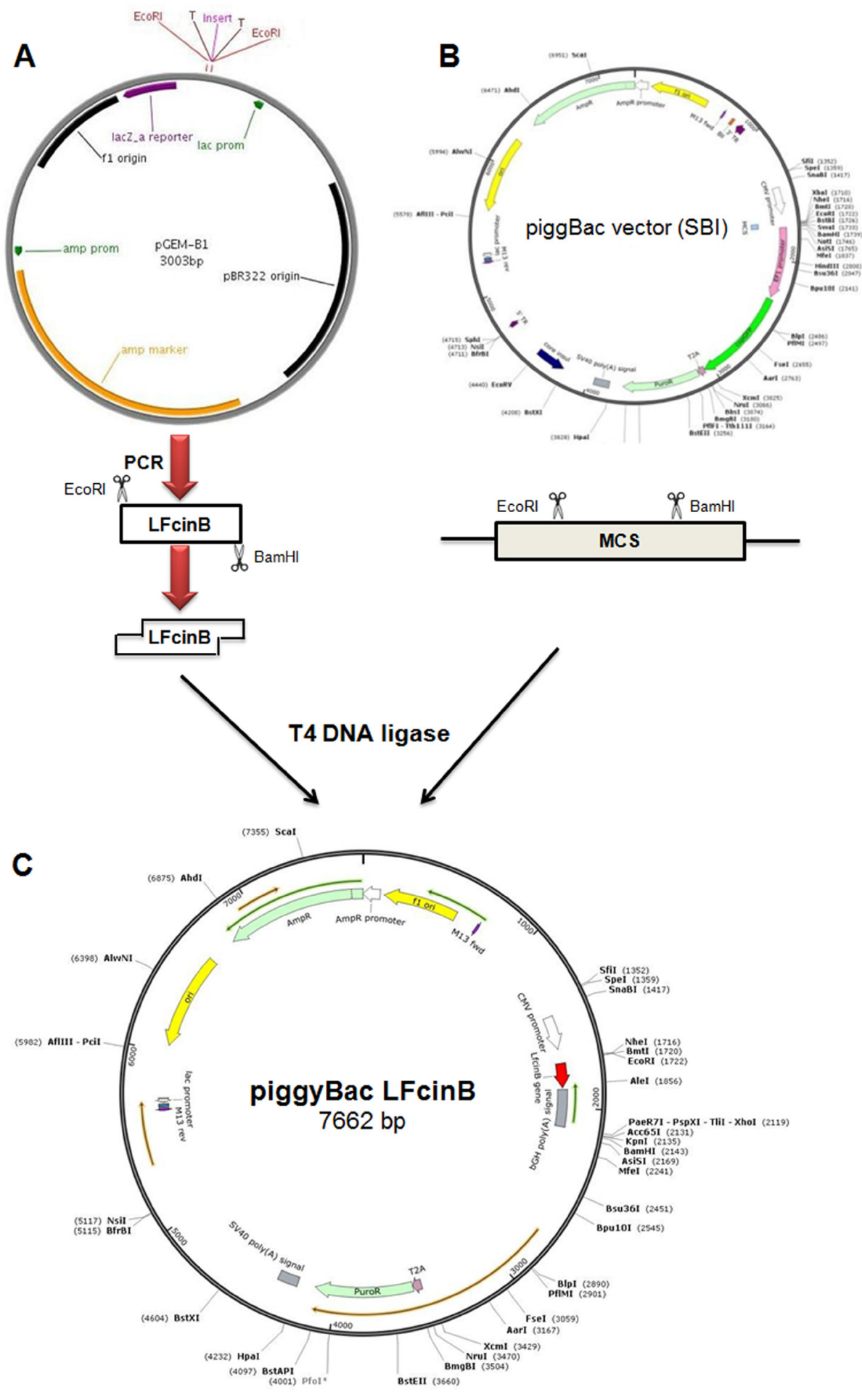

Figure 8: Schematic representation of purification of transgene and construction of recombinant PiggyBac-LFcinB vector. (A) Isolation of bovine lactoferricin from pGEM-B1 plasmid by double digestion with EcoRI and BamHI restriction enzymes; (B) Targeted PiggyBac cloning vector to construct recombinant vector; (C) Constructed recombinant PiggyBac-LFcinB vector (7662 bp). 
further applications such as genetic engineering and gene therapy in livestock.

Designing and insertion of a new hybrid peptide PiggyBac-LFcinB in between BamHI and EcoRI lead to formation of recombinant expression vector for heterologous expression of PiggyBac-LFcinB in $E$. coli top10. The recombinant showed antimicrobial activity assayed by micro-dilution and agar-well diffusion methods. Bi et al. [38], demonstrated the bovine lactoferricin antimicrobial activity assayed by agar diffusion test only. Lactoferricin was shown to interact with lipopolysaccharide (LPS) of the Gramnegative bacterial membrane of E. coli [39] hence it has high antibacterial activity against $E$. coli [40]. Our findings also showed the comparatively higher antibacterial property of bovine lactoferricin against $E$. coli in comparison to $S$. aureus. Kutila et al. [41], have reported antibacterial property of bovine lactoferrin against bovine udder pathogens. Simojokia et al. [42], have been reported that high concentration of human lactoferrin in milk of rhLf-transgenic cows relieves signs of bovine experimental Staphylococcus chromogenes intramammary infection. While a study on recombinant human lactoferrin (rhLf) transgenic cows in an E. coli mastitis model and reported inconclusive results [43]. They have reported that rhLf-transgenic cows showed milder systemic signs and lower serum cortisol and haptoglobin concentrations than did controls. However, Lf does not seem to be a very efficient protein for genetic engineering to enhance the mastitis resistance of dairy cows. But mastitis is caused by not only due to E. coli, hence it could therapeutic effect in other type of mastitis as the report of other researcher [42].

The most striking observation have been reported by Lacasse et al. [44], that Lf increases the inhibitory activity of penicillin up to 4-fold in most penicillin-susceptible Staphylococcus aureus strains, whereas this increase was 4- to 16-fold in penicillin-resistant strains.

Nuclear magnetic resonance (NMR) study of Hwang et al. [45], demonstrated that free LFcinB adopts a conformation in an aqueous solution that is quite different from that found in the intact protein. During this phase, peptide loses the $\alpha$-helix seen in intact bovine lactoferrin (bLF) and forms a twisted $\beta$-sheet and resulting peptide becomes markedly amphipathic. The property of LFcinB to form amphipathic structures with clear hydrophobic and positively charged faces is a characteristic antibacterial trait they share with other peptides that display antimicrobial activity. Now it is well established that iron-independent mechanisms such as direct interaction with bacteria leading to membrane destabilization, modulation of bacteria motility, aggregation or endocytosis into host cells, inhibition of adherence and biofilm formation are responsible for the antimicrobial property of lactoferricin [46].

Lactoferricin (LFcin) antimicrobial potential is conferred in its ability to perturb membrane structure and it also act in synergism with other microbial agents. LFcin exhibits numerous biological activities in common with those of lactoferrin (LF). Whereas LFcin suppresses the activation of innate immunity by microbial components such as lipopolysaccharide (LPS) and CpG DNA, the peptide itself activates immunity. Administration of LFcin analogs has been shown to protect the host via direct antimicrobial activity and immunostimulatory effects in several infection models [47]. Ellison et al. [48], have shown other synergistic effects: the secretory IgA-Lf complex from human milk has bactericidal activity against both Gram-positive and Gram-negative bacteria. Thus oral immunization by mothers may help protect their infants.

For many years, the antimicrobial activity of lactoferricin was attributed to their ability to sequester iron thereby depriving potential pathogens of this essential nutrient. Our findings raise the possibilities to develop the cows with an effective antimicrobial defense system in the udder compartment after transplanting LFcinB transfected bMESCs to provide strong udder immunity against mastitis causing organisms. Owing to antibacterial activity of LFcinB that would be a promising candidate to replace conventional therapy of mastitis in dairy cows using antibiotic, which has been identified to be related to severe antibiotics resistance. Present findings may also open the possible use of bovine mammary gland as the non-genetically modified organism (non-GMO) bioreactor for the bulk production of proteins of pharmaceutical interest. A Recent study has been tried to use bovine mammary gland as a bioreactor for the production of human lactoferrin, but they generated transgenic cattle [49].

Of particular significance in the context of this report is the ability to introduce transgenes into bovine mammary stem cells to produce proteins of interest, including those usually present in cow milk, is an important discovery. This finding could have many applications in biotechnology considering the high milk output that can be obtained from high milk producing breeds of cattle and the ease of protein recovery from secreted milk.

LFcinB advantage of being a broad antibacterial spectrum without inducing resistance against antibiotics, amplifies its potential for use as an alternative to widely used antibiotics in the management of bovine mastitis, and would be the cost effective for the production of LFcinB in large scale for pharmaceutical industry. Large-scale production of biopharmaceuticals by current bioreactor techniques is limited by low transgenic efficiency and low expression of foreign proteins [49]. It could partly replace the use of antimicrobials, which cause problems due to their presence in the form of residues in milk and therefore, potentiate the risk for emergence of resistance. 


\section{MATERIALS AND METHODS}

\section{Reagents and chemicals}

All the chemicals used in the preparation of reagents, buffers, and the preparation of bacterial culture media (broth and agar) were of analytical grade purchased from Becton, Dickison and Company, France except sodium chloride from Georgiachem Co. Korea and Brain Heart Infusion (BHI) broth from Acumedia, Neogene, Scotland, UK. The restriction enzymes and T4 DNA ligation kit were purchased from Enzynomics, Korea and Invitrogen, USA, respectively. Primers were synthesized by Cosmo Genentech, Korea. The Exprep plasmid SV mini plasmid purification kit and Expin Gel DNA gel extraction kit were procured from Gene All Biotechnology, Korea. PCR cleanup kit was purchased from Genet Bio, Korea. Bovine mammary epithelial stem cells were characterized and preserved in our lab. All plastic-wares including cell culture flasks and plates were purchased from Nunc, Thermo Scientific, Korea. Dulbecco's Modified Eagle's Medium/F12 (DMEM/F12), penicillin-streptomycin and growth factors were purchased from Gibco, USA and Sigma, USA respectively. Fetal calf serum (FBS) was purchased from Hyclone, USA. Total easy-Blue RNA extraction kit and E. coli Top10 competent cells were procured from Intron Biotech, Korea. Puromycin and Ampicillin were purchased from Georgiachem Co. Korea.

\section{Bacterial strains, plasmids and growth conditions}

Plasmid cloning vector PiggyBac was procured from Clontech, USA (Catalogue No. PB513B-1) which contains green fluorescence protein (GFP). Escherichia coli Top10 cells were used as maintenance host for the propagation of plasmid. E. coli Top10 was grown in LuriaBertani (LB) broth aerobically at $37^{\circ} \mathrm{C}$. Agar plates were made by adding $1.5 \%(\mathrm{w} / \mathrm{v})$ agar to the liquid media. $E$. coli transformants were selected on LB plates containing $100 \mu \mathrm{g} / \mathrm{ml}$ Ampicillin (Sigma, USA).

\section{Synthesis and isolation of $L F c i n B$ gene}

The $449 \mathrm{bp}$ full-length bovine lactoferricin was synthesized commercially by Bioneer, Korea, and cloned segment was obtained into the pGEM-B1 vector system. The detection of the $L F C i n B$ gene into the pGEM-B1 was carried out using detection primers that were 18-mer oligonucleotide (Forward: 5'-CCC TGC TGT CCC TTG GAG-3') and 20-mer oligonucleotide (Reverse: 5'-TAA AAG GCC CTC CTCA CACA-3'). The supplied vector was linearized using BamHI and the targeted gene was isolated (449 bp) by polymerase chain reaction (PCR).

The cloning primers (Forward 5'-ATA GAT CTG ATA TCG CTA GCG AAT TCA AGC-3' and Reverse 5'TAG GAT CCG ATA TCG GTA CCG CCG GGC TCG
AGC C-3') containing restriction sites for EcoRI and BamHI in the forward and reverse primers respectively, were designed for subcloning. PCR amplification was performed using the following programme: $95^{\circ} \mathrm{C}$ for $5 \mathrm{~min}, 95^{\circ} \mathrm{C}$ for $30 \mathrm{~s}, 67^{\circ} \mathrm{C}$ for $30 \mathrm{~s}$ and $72^{\circ} \mathrm{C}$ for $1 \mathrm{~min}$, cycle was repeated 35 times, a final extension at $72^{\circ} \mathrm{C}$ for $10 \mathrm{~min}$. A $50-\mu \mathrm{L}$ PCR reaction volume was used with a 10 pmole concentration using the Prime Taq DNA polymerase kit (Genet Bio, Korea). PCR products were separated on a 1-2\% agarose gel and extracted by Expin Gel DNA gel extraction. The amplified PCR product $(1 \mu \mathrm{g})$ and expression vector PiggyBac $(1 \mu \mathrm{g})$ were digested with $1 \mu \mathrm{l}(20 \mathrm{U} / \mu \mathrm{l})$ of the restriction enzymes EcoRI and BamHI. Two microliters of EZ-One buffer was added in a total reaction volume of $20 \mu \mathrm{l}$, incubated at $37^{\circ} \mathrm{C}$ for $15 \mathrm{~min}$ followed by inactivation at $65^{\circ} \mathrm{C}$ for $20 \mathrm{~min}$. The samples that were ready for ligation were kept at $-20^{\circ} \mathrm{C}$.

\section{Cloning of $L F c i n B$ into mammalian cell-specific expression vector PiggyBac}

The strategy for the construction of the mammaryspecific expression vector PiggyBac harboring recombinant $L F$ cinB gene is shown (Figure 8). CMV and EF1 promoters as present in the Piggybac backbone were enough for the expression of lactoferricin and GFP. The ligation reactions were performed using a T4 DNA ligation kit according to the manufacturer's instructions (Enzynomics, Korea). PCR products, LFcinB flanking with bovine signal peptide and bovine growth hormone polyA was cloned into mammalian expression vector PiggyBac (7258 bp) with a 1:3 molar ratio of vector and insert for ligation at the EcoRI and $\mathrm{BamHI}$ sites. The reaction mixture was incubated overnight $(12 \mathrm{~h})$ at $18^{\circ} \mathrm{C}$ with $1 \mu \mathrm{L}$ of T4 DNA ligase enzyme (400 $\mathrm{U} / \mu \mathrm{L}$ ). The reaction was stopped by incubating at $60^{\circ} \mathrm{C}$ for $20 \mathrm{~min}$. After completing the ligation process, the ligation mixture was immediately transformed into E. coli Top 10 competent cells with $100 \mu \mathrm{g} / \mathrm{ml}$ ampicillin as the selection marker. After $12-13 \mathrm{~h}$ of incubation at $37^{\circ} \mathrm{C}$, a single colony was selected and grown in $3 \mathrm{ml}$ broth at $37^{\circ} \mathrm{C}$ for $8 \mathrm{~h}$. The positive transformants were selected by PCR screening.

The plasmid with the desired gene was designated as PiggyBac-LFcinB (Figure 8) and was subjected to ligation confirmation by single and double digestion. The product was evaluated by agarose gel electrophoresis. The clone (PiggyBac-LFcinB) was further confirmed by DNA sequencing (Bioneer Co., Korea). The end product of recombinant PiggyBac-LFcinB was subjected for endotoxin free using 10\% Triton X-114 and subsequently used for transfection in the target cells.

\section{Cell culture, transfection and selection of stable cell line}

Bovine mammary epithelial stem cells (bMESCs) were collected from Korean Holstein cows and maintained in tissue culture flasks in Dulbecco's Modified Eagle's 
Medium/F12 (DMEM/F12) supplemented with 10\% fetal bovine serum, $5 \mu \mathrm{g} / \mathrm{ml}$ insulin, $10 \mathrm{ng} / \mathrm{ml}$ epidermal growth factor (EGF), $10 \mathrm{ng} / \mathrm{ml}$ basic fibroblast growth factor (bFGF), $100 \mathrm{unit} / \mathrm{ml}$ penicillin, $100 \mu \mathrm{g} / \mathrm{ml}$ streptomycin, $100 \mu \mathrm{g} / \mathrm{ml}$ gentamicin and $2.5 \mu \mathrm{g} / \mathrm{ml}$ amphotericin B with the seeding rate of $1 \times 10^{5} / 25 \mathrm{~cm}^{2}\left(4000\right.$ cells $\left./ \mathrm{cm}^{2}\right)$ tissue culture flask [50].

The cells (bMESCs) were subcultured for 2-3 days after attaining the confluency of approximately $90 \%$ and fresh medium was added $24 \mathrm{~h}$ before transfection. Trypsinized 90\% confluent cultured cells were washed twice with phosphate buffer saline (PBS, pH 7). 1-2 x $10^{6}$ cells were transfected with linearized PiggyBacLFcinB plasmid $(10 \mu \mathrm{g})$ using Amaxa Human mammary epithelial cells (HMEC) nucleofector ${ }^{\mathrm{TM}} \mathrm{kit}$, and the supplied protocol was followed after some modifications. The ratio of PiggyBac transposon vector clone and PiggyBac transposase vector (PB210PA-1) was optimized as 2.5:1 for the successful transfection. Nucleofection was performed using U-029 program of Amaxa NucleofectorII system and $5 \mu \mathrm{g}$ Pmax Green Fluorescent Protein (GFP) vector (Lonza, Amaxa) containing GFP gene was used as positive control. bMESCs are very hard to transfect, hence current study optimized dimethyl sulfoxide (DMSO, Sigma, USA) concentration and used as $1.6 \%$ in transfection reagent and for $24 \mathrm{~h}$ after the pulse. After nucleofection, cells were cultured in the DMEF/ F12 growth medium supplemented with 20\% FBS. After $48 \mathrm{~h}$ of transfection, cells were incubated with $250 \mu \mathrm{g} /$ $\mathrm{ml}$ puromycin for 2-3 weeks. Pure, stable cell lines were stored in DMEM/F12 supplemented with $20 \%$ FBS and $10 \%$ DMSO for further analysis.

\section{Detection of $L F c i n B$ into stable cell lines by immunocytochemistry}

Transfected bMESCs were seeded in a 24-well plate, and at $60 \%$ confluence were used for immunostaining. Cells were fixed in 4\% paraformaldehyde for $30 \mathrm{~min}$ at $4^{\circ} \mathrm{C}$, then treated with $0.2 \%$ Triton $\mathrm{X}-100$ for $30 \mathrm{~min}$ at $4^{\circ} \mathrm{C}$, followed by treatment with $0.3 \% \mathrm{H}_{2} \mathrm{O}_{2}$ for $10 \mathrm{~min}$ to stop endogenous peroxidase activity. To prevent nonspecific binding, cells were incubated with $10 \%$ goat serum for $1 \mathrm{~h}$ at $4^{\circ} \mathrm{C}$. After they had been washed thrice with PBS, the cells were subjected to immunostaining with Mouse monoclonal Lactoferricin B antibody (MyBiosource.com) primary antibody supplemented at a dilution of 1:5 and incubated for overnight at $4{ }^{\circ} \mathrm{C}$ in the dark humidity area. For visualization, fluorescence secondary antibodies for goat anti-mouse conjugated with Phycoerythrin (PE; Santa Cruz, USA) was added at a dilution of 1:50. To visualize nuclei, the cells were counterstained with $0.3 \mu \mathrm{g} / \mathrm{ml} \mathrm{4,6-diamidino-}$ 2-phenylindole (DAPI) (Sigma, USA) for $10 \mathrm{~min}$. Immunostained cells were observed under a fluorescence microscope (Olympus, Japan).

\section{$L F \operatorname{cin} B$ secretion ability of transfected bovine mammary epithelial stem cells}

The bovine lactoferricin secretion ability of bMESCs was confirmed by the estimation of lactoferricin concentration in the cultured medium of lactoferricin transfected and non-transfected cells as a control. The transfected and non-transfected bMESCs $\left(1 \times 10^{5}\right.$ cells/well) were cultured in growth medium (DMEM/ F12) contained in 24-well plate. Media from both the transfected and non-transfected cells was harvested after 3 days of culture and concentration of lactoferrin was determined using the bovine lactoferrin ELISA kit (Cusabio). Media from non-transfected cells was used as a control.

\section{Bacterial culture and antibacterial activity of LFcinB}

Bovine mastitis causing bacteria Staphylococcus aureus and Escherichia coli were isolated directly from clinical cases of bovine mastitis milk using standard protocols of isolation and characterization of isolated bacterial species. After species had been confirmed, the antibacterial activity of LFcinB against both bacteria was evaluated by various antimicrobial assays. All the tests were conducted in triplicates, and results are expressed as mean \pm standard deviation (SD).

To test the antimicrobial activity of LFcinB, FBS and antibiotic-free media from the transfected bMESCs were analyzed for antibacterial activity. The antimicrobial activity was determined by agar-well diffusion method $[51,52]$. S. aureus and E. coli were grown in Brain Heart Infusion (BHI) broth and incubated for $24 \mathrm{~h}$ at $37^{\circ} \mathrm{C} .100$ $\mu \mathrm{l}$ of bacterial suspension containing $1 \times 10^{5} \mathrm{CFU} / \mathrm{ml}$ of each bacterium was spread over the Mueller-Hinton Agar medium, $10 \mathrm{~mm}$ wells were prepared and filled with 100 $\mu \mathrm{l}$ media from transfected cells. Penicillin-streptomycin $(50 \mu \mathrm{g} / \mathrm{ml})$ was used as positive control for $S$. aureus and gentamicin $(50 \mu \mathrm{g} / \mathrm{ml})$ for $E$. coli, and media from nontransfected cells were used as negative controls in both the assays. Petri dishes inoculated with the microorganism and containing test samples were incubated at $34^{\circ} \mathrm{C}$ for $24 \mathrm{~h}$. The antibacterial activity was determined by measuring the zone of inhibition (in $\mathrm{mm}$ ) around each well. The zone of inhibition measuring $\leq 10 \mathrm{~mm}$ is considered resistant and higher than that as susceptible [53].

A kinetic study of the antimicrobial activity of recombinant LFcinB against major mastitis causing bacteria was conducted by broth micro-well assay, following the protocol described by Lourenco and Pinto [54] after slight modifications. The wells in a 96 well plate were inoculated with $100 \mu$ l containing $\sim 1 \times 10^{5} \mathrm{CFU}$ of $S$. aureus and $E$. coli bacteria and media from transfected and non-transfected bMESCs followed by incubation at $37^{\circ} \mathrm{C}$ for $24 \mathrm{~h}$ in $\mathrm{BHI}$ broth. The plates were analyzed 
for turbidity by measuring the optical density at 595 $\mathrm{nm}$ by using a microplate reader (Model-680, Bio-Rad). Penicillin-streptomycin $(100 \mu \mathrm{g} / \mathrm{ml})$ and gentamicin $(50$ $\mu \mathrm{g} / \mathrm{ml}$ ) were used as positive controls for $S$. aureus and for $E$. coli respectively, while media from non-transfected were used as negative controls in both assays.

\section{Statistical analysis}

All experiments were performed in triplicates and data were expressed as the mean \pm standard deviation (SD). All analyzes were performed using SPSS 16 (SPSS Institute, Cary, NC, USA); individual comparisons were made using Tukey's multiple-range test, which was used to determine the differences between the means. $P$-value of $<0.05$ were considered significant.

\section{Abbreviations}

LFcinB, bobine lactoferricin, bMESCs, bovine mammary epithelial stem cells, ELISA, enzyme-linked immunosorbent assay, $S$. aureus, Staphylococcus aureus, E. coli, Escherichia coli, LF, Lactoferrin, AMPs, antimicrobial peptides, BLASTn, balignment search toolnucleotide, GFP, green fluorescent protein, iPSCs, induced pluripotent stem cells, LPS, lipopolysachharide, LFcin, lactoferricin, NMR, nuclear magnetic resonance, rhLf, recombinant human lactoferrin, $\mathrm{BHI}$, brain heart infusion, FBS, fetal calf serum, PCR, polymerase chain reaction, DMEM/F12, Dulbecco's Modified Eagle's Medium/ F12, LB, luria-bertani, CMV, cytomegalovirus, EGF, epidermal growth factor, bFGF, basic fibroblast growth factor, bp, basepair, DNA, deoxyribonuclic acid, RNA, ribouclic acid, HMEC, human mammary epithelial cells, PE, phycoerythrin, DAPI, diamidino-2-phenylindole, SD, standard deviation.

\section{Author contributions}

Neelesh Sharma, Dong Kee Jeong, Amit Kumar Singh, Mrinmoy Ghosh and Nam Eun Kim participated in designing the study. Neelesh Sharma and Do Luong Huynh conducted the study. Data was analysed by Sung Woo Kim, Simrinder Singh Sodhi. Chemical and reagent supply was managed by Dong Kee Jeong. Manuscript was written and reviewed by Neelesh Sharma, Dong Kee Jeong, Sung Jin Lee, Kafil Hussain and Sung Jong Oh.

\section{CONFLICTS OF INTEREST}

The author(s) declare that they have no conflict of interest.

\section{ACKNOWLEDGMENTS AND FUNDING}

This work was supported by the grant Korea Institute of Planning and Evaluation for Technology in
Food, Agriculture, Forestry and Fisheries (IPET) through Agri-Bio industry Technology Development Program, funded by Ministry of Agriculture, Food and Rural Affairs (MAFRA) (No. 2016300060), Republic of Korea. We are also grateful to the Indian Council of Agricultural Research (ICAR), New Delhi, India (Grant number: 29$1 / 2009-E Q R / E d n)$, for providing the ICAR-International fellowship to the first author.

\section{REFERENCES}

1. Sharma N, Kang TY, Lee SJ, Kim JN, Hur CH, Ha JS, Vohra V, Jeong D.K. Status of bovine mastitis and associated risk factors in Subtropical-Jeju Island, South Korea. Trop Anim Hlth Prod. 2013; 45:1829-1832.

2. Sharma N, Maiti SK. Incidence, etiology and antibiogram of subclinical mastitis in cows in Durg, Chhattisgarh. Indian. J Vet Res. 2010; 19:45-54.

3. Dharmik PG, Gomashe AV. Isolation, characterization and antibiotic susceptibility profile of Staphylococcus aureus from raw milk samples in Nagpur district, India. J Appl Nat Sci. 2011; 3:319-322.

4. Adlerova L, Bartoskova A, Faldyna M. Lactoferrin: a review. Vet Medicina (Praha). 2008; 53:457-468.

5. Gonzalez-Chavez SA, Arévalo-Gallegos S, Rascón-Cruz Q. Lactoferrin: structure, function and applications. Int J Antimicrob Agents. 2009; 33:301.e1-301.e8.

6. Berlutti F, Pantanella F, Natalizi T, Frioni A, Paesano R, Polimeni A, Valenti P. Antiviral properties of lactoferrin- A natural immunity. Molecule. 2011; 16:6992-7018.

7. Jenssen H, Hancock R. Antimicrobial properties of lactoferrin. Biochimie. 2009; 91:19-29.

8. Legrand D, Mazurier J. A critical review of the roles of host lactoferrin in immunity. Biometals. 2010; 23:65-376.

9. Cooper CA, Maga EA, Murray JD. Production of human lactoferrin and lysozyme in the milk of transgenic dairy animals: past, present, and future. Transgenic Res. 2015; 24:605-614.

10. Benkerroum N. Antimicrobial peptides generated from milk proteins: a survey and prospects for application in the food industry- a review. Int J Dairy Tech. 2010; 63:320-338.

11. Lohner K. New strategies for novel antibiotics: peptides targeting bacterial cell membranes. Gen Physiol Biophys. 2009; 28:105-116.

12. Lohner K, Blondelle SE. Molecular mechanisms of membrane perturbation by antimicrobial peptides and the use of biophysical studies in the design of novel peptide antibiotics. Comb Chem High Throughput Screen. 2005; 8:241-256.

13. Gazit E, Boman A, Boman HG, Shai Y. Interaction of the mammalian antibacterial peptide cecropin P1 with phospholipids vesicles. Biochem. 1995; 34:11479-11488.

14. Heller WT, Waring AJ, Lehrer RI, Harroun TA, Weiss TM, Yang L, Huang HW. Membrane thinning effect of 
the beta-sheet antimicrobial protegrin. Biochem. 2000; 39:139-145.

15. Ulvatne H, Samuelsen Ø, Haukland HH, Krämer M, Vorland LH. Lactoferricin B inhibits bacterial macromolecular synthesis in Escherichia coli and Bacillus subtilis. FEMS Microbiol Lett. 2004; 237:377-384.

16. Bellamy WR, Takase M, Wakabayashi H, Kawase K, Tomita M. Antibacterial spectrum of lactoferricin B, a potent bactericidal peptide derived from the N-terminal region of bovine lactoferrin. J Appl Bacterio. 1992; 173:472-479.

17. Farnaud S, Evans RW. Lactoferrin - a multifunctional protein with antimicrobial properties. Mol Immunol. 2003; 40:395-405.

18. Zhang JX, Zhang SF, Wang TD, Guo XJ, Hu RL. Mammary gland expression of antibacterial peptide genes to inhibit bacterial pathogens causing mastitis. J Dairy Sci. 2007; 90:5218-5225.

19. Tomita M, Bellamy W, Takase M, Yamauchi K, Wakabayashi H, Kawase K. Potent antibacterial peptides generated by pepsin digestion of bovine lactoferrin. J Dairy Sci. 1991; 74:4137-4142.

20. Strom MB, Rekdal O, Svendsen JS. Antibacterial activity of 15-residue lactoferricin derivatives. J Pept Res. 2000; 56:265-274.

21. Haug BE, Svendsen JS. The role of tryptophan in the antibacterial activity of a 15-residue bovine lactoferricin peptide. J Pept Sci. 2001; 7:190-196.

22. Orsi N. The antimicrobial activity of lactoferrin: current status and perspectives. Biometals. 2004; 17:189-196.

23. Jahani S, Shakiba A, Jahani L. The Antimicrobial effect of lactoferrin on Gram-negative and Gram-positive bacteria. Int J Infect. 2015; 2:e27954.

24. Gifford JL, Hunter HN, Vogel HJ. Lactoferricin: a lactoferrin- derived peptide with antimicrobial, antiviral, antitumor and immunological properties. Cell. Mol. Life. Sci. 2005; 62:2588-2598.

25. Lohuis JACM, Hensen SM, Beers H. Effect of lactoferrin and cephapirin, alone and in combination on growth of $\mathrm{E}$. coli strains from mastitis. 3rd Int Mast Sem Proc II. 1995; 110-111.

26. Diarra MS, Peticlerc D, Lacasse P. Effect of lacto-lactoferrin in combination with penicillin on the morphology and the physiology of Staphylococcus aureus isolated from bovine mastitis. J Dairy Sci. 2002; 85:1141-1149.

27. Wall RJ, Powell AM, Paape MJ, Kerr DE, Bannerman DD, Pursel VG, Wells KD, Talbot N, Hawk HW. Genetically enhanced cows resist intramammary Staphylococcus aureus infection. Nature Biotech. 2005; 23:445-451.

28. Kerr DE, Wellnitz O. Mammary expression of new genes to combat mastitis. J Anim Sci. 2003; 81:38-47.

29. Flores-Villasenor H, Canizalez-Roman A, Reyes-Lopez M, Nazmi A, de la Garza M, Zazueta-Beltran J, Leon-Sicairos N, Bolscher JGM. Bactericidal effect of bovine lactoferrin,
LFcin, LFampin and LFchimera on antibiotic-resistant Staphylococcus aureus and Escherichia coli. Biometals. 2010; 23:569-578.

30. León-Calvijo MA, Leal-Castro AL, Almanzar-Reina GA, Rosas-Pérez JE, García-Castañeda JE, Rivera-Monroy ZJ. Antibacterial activity of synthetic peptides derived from lactoferricin against Escherichia coli ATCC 25922 and Enterococcus faecalis ATCC 29212. BioMed Res Int. 2015. https://doi.org/10.1155/2015/453826.

31. Ding S, Wu X, Li G, Han M, Zhuang Y, Xu T. Efficient transposition of the PiggyBac (PB) transposon in mammalian cells and mice. Cell. 2005; 122:473-483.

32. Li MA, Turner DJ, Ning Z, Yusa K, Liang Q, Eckert S, Rad L, Fitzgerald TW, Craig NL, Bradley A. Mobilization of giant PiggyBac transposons in the mouse genome. Nucleic Acids Res. 2011; 39:e148.

33. Owens JB, Urschitz J, Stoytchev I, Dang NC, Stoytcheva Z, Belcaid M, Maragathavally KJ, Coates CJ, Segal DJ, Moisyadi S. Chimeric PiggyBac transposases for genomic targeting in human cells. Nucleic Acids Res. 2012; 40:146699-146978.

34. Park TS, Han JY. PiggyBac transposition into primordial germ cells is an efficient tool for transgenesis in chickens. PNAS. 2012; 109:9337-9341.

35. Kawaguchi T, Tsukiyama T, Kimura K, Matsuyama S, Minami N, Yamada M, Imai H. Generation of naïve bovine induced pluripotent stem cells using PiggyBac transposition of doxycycline-inducible transcription factors. PLoS One. 2015; 10:e135403.

36. Li AM, Pettitt SJ, Eckert S, Ning Z, Rice S, Cadinanos J, Yusa K, Conte N, Bradley A. The PiggyBac transposon displays local and distant reintegration preferences and can cause mutations at noncanonical integration sites. Mol Cell Biol. 2013; 33:1317-1330.

37. Wu SCY, Meir YJJ, Coates CJ, Handler AM, Pelczar P, Moisyadi S. PiggyBac is a flexible and highly active transposon as compared to Sleeping Beauty, Tol2, and Mos1 in mammalian cells. PNAS. 2006; 103:15008-15013.

38. Bi C, Feng X, Shan A, Guo J. Cloning and expression of a gene encoding shortened LfcinB(1-15)-Melittin(5-12) hybrid peptide in Escherichia coli BL21 DE3. Sheng Wu Gong Cheng Xue Bao. 2009; 25:975-81.

39. Appelmelk BJ, An YQ, Geerts M, Thijs BG, de Boer HA, MacLaren DM, de Graaff J, Nuijens JH. Lactoferrin is a lipid A-binding protein. Infect Immun. 1994; 62:2628-2632.

40. León-Calvijo MA, Leal-Castro AL, Almanzar-Reina GA, Rosas-Pérez JE, García-Castañeda JE, Rivera-Monroy ZJ. Antibacterial activity of synthetic peptides derived from lactoferricin against Escherichia coli ATCC 25922 and Enterococcus faecal is ATCC 29212. BioMed Res Int. 2015; 1-8.

41. Kutila T, Pyorala S, Saloniemi H, Kaartinen L. Antibacterial effect of bovine lactoferrin against udder pathogens. Acta Vet Scand. 2003; 44:35-42. 
42. Simojokia H, Hyvonenb P, Orroc T, Pyorala S. High concentration of human lactoferrin in milk of rhLftransgenic cows relieves signs of bovine experimental Staphylococcus chromogenes intramammary infection. Vet Immunol Immunopathol. 2010; 136:265-271.

43. Hyvonen P, Suojala L, Orro T, Haaranen J, Simola O, Røntved C, Pyorala S. Transgenic cows that produce recombinant human lactoferrin in milk are not protected from experimental Escherichia coli intramammary infection. Infect Immun. 2006; 74:6206-6212.

44. Lacasse P, Lauzon K, Diarra MS, Petitclerc D. Utilization of lactoferrin to fight antibiotic-resistant mammary gland pathogens. J Anim Sci. 2008; 86:66-67.

45. Hwang PM, Zhou N, Shan X, Arrowsmith CH, Vogel HJ. Three-dimensional solution structure of lactoferricin B, an antimicrobial peptide derived from bovine lactoferrin. Biochem. 1998; 37:4288-4298.

46. Roseanu A, Florian P, Condei M, Cristea D, Damian M. Antibacterial activity of lactoferrin and lactoferricin against oral Streptococci. Rom Biotechnol Lett. 2010; 15:5788-5792.

47. Wakabayashi H, Takase M, Tomita M. Lactoferricin derived from milk protein lactoferrin. Curr Pharm Des. 2003; 9:1277-1287.

48. Ellison RT III, LaForce FM, Giehl TJ, Boose DS, Dunn BE. Lactoferrin and transferrin damage of the Gram-negative outer membrane is modulated by $\mathrm{Ca} 2+$ and $\mathrm{Mg} 2+$. J Gen Microbiol. 1990; 136:1437-1446.

49. Yang P, Wang J, Gong G, Sun X, Zhang R, Du Z, Liu Y, Li R, Ding F, Tang B, Dai Y, Li N. Cattle mammary bioreactor generated by a novel procedure of transgenic cloning for large-scale production of functional human lactoferrin. PLoS One. 2008; 3:e3453.

50. Sharma N, Kim JH, Sodhi SS, Luong DH, Kim SW, Oh SJ, Jeong DK. Differentiation dynamics of mammary epithelial stem cells from Korean Holstein dairy cattle under ECMfree conditions. J Biomol Struct Dyn. 2015; 33:2633-2654.

51. Cappuccino S. 1999. Micro-A laboratory manual. Addison. Wesley. Longman. Inc. 254-256.

52. Espitia PJP, Soares NFF, Teofilo RF, Vitor DM, Coimbra JSR, Andrade NJ, Sousa FB, Sinisterra RD, Medeiros EAA. Optimized dispersion of $\mathrm{ZnO}$ nanoparticles and antimicrobial activity against foodborne pathogens and spoilage microorganisms. J Nanopart Res. 2013; 15:1324-1339.

53. Johnson T, Case C. Chemical methods of control. In: Laboratory Experiments in Microbiology, Brief Edition, 4th ed. Redwood City, CA. Benjamin/Cummings. Publishing. Co. 1995.

54. Lourenco FR, Pinto TJA. Antibiotic microbial assay using kinetic-reading microplate system. Brazalian J Pharma Sci. $2011 ; 47: 573-584$. 